\title{
Clinical Characteristics of Chronic Obstructive Pulmonary Disease in Female Patients: Findings from a KOCOSS Cohort
}

This article was published in the following Dove Press journal: International Journal of Chronic Obstructive Pulmonary Disease

Joon Young Choi, ${ }^{1, *}$ Shin Young Kim, (iD) ${ }^{2, *}$ Jae Ha Lee, (iD ${ }^{3}$ Yong Bum Park, (iD) ${ }^{4}$ Yee Hyung Kim, ${ }^{5}$ Soo-jung Um, (iD ${ }^{6}$ Ki Suck Jung, ${ }^{7}$ Kwang $\mathrm{Ha}$ Yoo, (iD) ${ }^{8}$ Seoung Ju Park, (iD) 9 Houng Kyu Yoon ${ }^{10}$

'Division of Pulmonary and Critical Care Medicine, Department of Internal Medicine, Incheon St. Mary's Hospital, College of Medicine, The Catholic University of Korea, Seoul, Republic of Korea; ${ }^{2}$ Division of Pulmonary, Allergy and Critical Care Medicine, Department of Internal Medicine, St. Vincent's Hospital, College of Medicine, The Catholic University of Korea, Seoul, Republic of Korea; ${ }^{3}$ Division of Pulmonology, Department of Internal Medicine, Inje University College of Medicine, Haeundae Paik Hospital, Busan, Republic of Korea; ${ }^{4}$ Division of Pulmonary, Allergy, and Critical Care Medicine, Department of Internal Medicine, Hallym University Kangdong Sacred Heart Hospital, Seoul 134-70I, Republic of Korea: ${ }^{5}$ Department of Pulmonary and Critical Care Medicine, Kyung Hee University Hospital at Gangdong, Kyung Hee University School of Medicine, Seoul, Republic of Korea; ${ }^{6}$ Division of Respiratory Medicine, Department of Internal Medicine, Dong-A University College of Medicine, Dong-A University Medical Center, Busan, Republic of Korea; 'Division of Pulmonary Medicine, Department of Internal Medicine, Hallym University Sacred Heart Hospital, Hallym University Medical School, Anyang, Republic of Korea; ${ }^{8}$ Division of Pulmonary, Allergy and Critical Care Medicine, Department of Internal Medicine, Konkuk University School of Medicine, Seoul, Republic of Korea; ${ }^{9}$ Division of Pulmonary, Allergy and Critical Care Medicine, Department of Internal Medicine, Jeonbuk National University Hospital, Jeonju, Republic of Korea; ${ }^{10}$ Division of Pulmonary and Critical Care Medicine, Department of Internal Medicine, Yeouido St Mary's Hospital, College of Medicine, The Catholic University of Korea, Seoul, Republic of Korea

*These authors contributed equally to this work.

Correspondence: Hyoung Kyu Yoon Division of Pulmonary and Critical Care Medicine, Department of Internal Medicine Yeouido St Mary's Hospital, College of Medicine, The Catholic University of Korea, \#62 Youido-Dong Yeongdeungpo-Gu, Seoul, Republic of Korea

$\mathrm{Tel}+82237792213$

Fax +8227803132

Email cmcyhg@gmail.com
Purpose: The prevalence of chronic obstructive pulmonary disease (COPD) in females has increased, changing the concept of COPD as a disease mostly limited to males. In this study, the clinical characteristics of COPD in females were investigated.

Patients and Methods: The study was based on a multicenter cohort of COPD patients recruited from 54 medical centers in South Korea. Sex-based differences in general characteristics, exposure risk factors, depression scores, results of pulmonary function tests, COPD exacerbation, symptom scores, and radiologic findings were evaluated. Sex-related differences in the annual $\mathrm{FEV}_{1}$ change over 5 years were analyzed in a linear mixed model. Results: Of the 2515 patients enrolled in this study, 8.1\% were female. Female patients who had a higher BMI and a lower level of education were less likely to be smokers, were more exposed to passive smoking/biomass, and were more depressed compared to males. The rates of bronchiectasis, previous childhood respiratory infection, and asthma were higher in females. Female patients also had more symptoms and a poorer exercise capacity than males, but no significant differences were observed in terms of exacerbations. Radiologic findings revealed that male patients had worse emphysema, and female patients had worse bronchiectasis, as determined based on chest X-ray and computed tomography findings. On pulmonary function tests, female patients had less obstruction and less annual $\mathrm{FEV}_{1}$ loss over 5 years.

Conclusion: This study revealed differences in the clinical parameters between male and female patients with COPD, including general characteristics, disease characteristics, and clinical outcomes.

Keywords: COPD, gender difference, KOCOSS database, cohort study

\section{Introduction}

Chronic obstructive pulmonary disease (COPD) is one of the most common diseases worldwide and causes significant morbidity and mortality. ${ }^{1}$ Although COPD was long thought to be mostly a disease of men, several studies have reported decreasing differences in COPD rates in males vs females, and in one study COPD was mostly observed in females. ${ }^{2-7}$ The shift in the sexual distribution of COPD reflects the increase in cigarette smoking in women over the past few decades, especially in developed countries, ${ }^{8}$ compounded by the greater susceptibility of women to the adverse effects of smoking. ${ }^{9}$ Other risk factors, such as coal dust and biomass, and the changing socioeconomic status and societal roles of women, must also be considered in understanding the changing prevalence of COPD. ${ }^{10}$ 
COPD is a heterogeneous disease with different phenotypes, such that an individualized approach to its assessment and treatment is needed. Based on clinical studies showing an increasing prevalence in females, the sexspecific characteristics of COPD should be investigated. Previous studies have reported that females with COPD are less likely to be smokers, have a lower body mass index (BMI), and are less likely to have emphysema or bronchiectasis. ${ }^{11-13}$ However, despite having better lung function, female COPD patients suffer from a larger number of symptoms and more frequent exacerbations. ${ }^{3,14,15}$ These features may be related to the socioeconomic status of each study population and thus its specific risk factors. Korea has rapidly changed from a developing to a developed country, so it may have unique features not only in terms of COPD but also its occurrence in males vs females. For example, Korean COPD patients may be frequently exposed to biomass, coal dust, or occupationally related hazardous substance, all of which are important risk factors in both developing and westernized developed countries with older populations. ${ }^{16}$

Therefore, in this study, we investigated sex-based differences in the clinical characteristics of COPD, by assessing the general characteristics of the disease in male vs female patients as well as sex-based differences in symptom scores, acute exacerbations, radiologic findings, and the results of pulmonary lung function tests (PFTs).

\section{Patients and Methods Study Design, Study Population, and Data Collection}

The Korea COPD Subgroup Study (KOCOSS) cohort is a multicenter cohort study of COPD patients recruited from 54 medical centers in South Korea. In this study, we extracted KOCOSS data from the cohort enrolled between April 2012 and October 2018. Inclusion criteria were South Korean patients age $>40$ years and with a post-bronchodilator forced expiratory volume in one second $\left(\mathrm{FEV}_{1}\right)$ /forced vital capacity (FVC) $\leq 70 \%$ of the normal predicted value. All data were obtained from case reports (CRF) completed by a physician or trained nurse. After the initial examination, all patients were evaluated at 6-month intervals.

\section{Clinical Characteristics}

Patient data collected at the initial visit included age, BMI, smoking history (current, ex-, never-smoker), passive smoking history, educational level ( $>9$ years of national education), residence (urban vs rural), biomass exposure, inhaler use, and comorbidities. The Beck Depression Inventory (BDI) score was calculated to determine moderate to severe depression based on a cut-off level $>18$. PFTs were performed annually; for this study, annual PFT results for 5 years were extracted.

The number of COPD exacerbations during a 1-year follow-up was determined and categorized as moderate to severe and severe. The need for mechanical ventilation during hospitalization was also recorded.

Sex-based differences in chronic bronchitis symptoms, mMRC score, SGRQ-C score, CAT score, and the 6-minute walk distance test were analyzed. Chronic bronchitis was defined as the presence of cough and sputum for at least 3 months per year during more than 2 consecutive years.

\section{Radiology}

Chest X-ray and computed tomography (CT) data were used to also divide patients into normal and abnormal finding groups based on a formal reading of the images by a radiologist. Patients in the abnormal findings group were further categorized as having: (1) emphysematous change, (2) tuberculosis destroyed lung, (3) airway wall thickening, and/or (4) bronchiectasis. Patients without imaging data were excluded from the analysis.

\section{Statistical Analyses}

Statistical analyses were performed using the R software (ver. 3.6.3; R Development Core Team, Vienna, Austria). Continuous variables are presented as the mean \pm standard deviation, and categorical variables as numbers and percentages. Differences in the clinical parameters of male and female patients were analyzed. Differences in the categorical and continuous variables between two groups were analyzed using a $\chi^{2}$ test and Student's $t$-test, respectively. A p-value $<0.05$ was considered to indicate statistical significance. A linear mixed model was used to evaluate the annual change in $\mathrm{FEV}_{1}$ in males vs females. We included age and smoking status as covariates.

\section{Ethics}

This study was conducted in accordance with the Declaration of Helsinki. All patients submitted written informed consent at study enrollment. Ethical approval was collected from the Ethics Committee of each 
participating medical center. The centers are listed in the Supplementary Material.

\section{Results}

\section{General Characteristics}

Of the 2515 patients included in this study, 203 (7.9\%) were female and $2312(90.5 \%)$ were male. Table 1 summarizes the differences in their general characteristics. The mean age was $69.2 \pm 8.0$ years and the difference between males and females was not significant. Female patients had a higher BMI than males $(23.7 \pm 3.9$ vs $22.9 \pm 3.3$, respectively) and had less education (26.0\% vs $46.4 \%$, respectively). The smoking history differed significantly in that the majority $(60.5 \%)$ of the female patients were never-smokers but $96.3 \%$ of the male patients were current or ex-smokers. However, exposure to passive smoking and biomass was significantly higher in females than in males (41.4\% vs $17.9 \%, \mathrm{p}<0.01 ; 89.2 \%$ vs $74.7 \%, \mathrm{p}<0.01$, respectively). The two sex did not differ significantly in inhaler use, with the exception of the use of inhaled corticosteroid plus long-acting $\beta$-agonists $(18.7 \%$ vs $12.2 \%$, respectively). A comparison of comorbidities and previous respiratory/allergic diseases revealed that female patients had higher rates of osteoporosis $(18.3 \%$ vs $2.8 \%$, respectively), bronchiectasis $(12.0 \%$ vs $7.2 \%$, respectively), respiratory infections during childhood $(32.7 \%$ vs $18.5 \%$, respectively), and asthma ( $44.1 \%$ vs $31.2 \%$,

Table I General Characteristics and Gender Difference of COPD Patients

\begin{tabular}{|c|c|c|c|c|}
\hline Subjects (n, \%) & $\begin{array}{l}\text { Overall } \\
(N=25 \mid 5)\end{array}$ & Female $(\mathrm{N}=203)$ & Male $(N=23 \mid 2)$ & p-value \\
\hline Age, years & $69.2 \pm 8.0$ & $68.8 \pm 9.3$ & $69.3 \pm 7.9$ & 0.50 \\
\hline BMI $\left(\mathrm{kg} / \mathrm{m}^{2}\right)$ & $23.0 \pm 3.3$ & $23.7 \pm 3.9$ & $22.9 \pm 3.3$ & $<0.01$ \\
\hline Smoking history & & & & $<0.01$ \\
\hline Current smoker & $663(26.8 \%)$ & $24(12.6 \%)$ & $635(28.0 \%)$ & \\
\hline Ex-smoker & 1615 (65.2\%) & 51 (26.8\%) & 1549 (68.3\%) & \\
\hline Never-smoker & 200 (8.1\%) & 115 (60.5\%) & 85 (3.7\%) & \\
\hline Passive smoking & 483 (19.8\%) & 79 (4I.4\%) & 399 (17.9\%) & $<0.01$ \\
\hline Education (>9years) & 1116 (45.0\%) & $51(26.0 \%)$ & $105 \mid(46.4 \%)$ & $<0.01$ \\
\hline Urban & 2007 (80.9\%) & $167(83.9 \%)$ & I 827 (80.6\%) & 0.30 \\
\hline Biomass exposure & I 804 (75.6\%) & 174 (89.2\%) & 1623 (74.7\%) & $<0.01$ \\
\hline Inhaler use & 2009 (78.6\%) & $156(76.8 \%)$ & I840 (79.6\%) & 0.41 \\
\hline LAMA & $572(22.4 \%)$ & 46 (22.7\%) & $522(22.6 \%)$ & 1.00 \\
\hline LABA & I58 (6.2\%) & 7 (3.4\%) & 149 (6.4\%) & 0.12 \\
\hline LABA/LAMA & 267 (10.4\%) & $20(9.9 \%)$ & 249 (10.7\%) & 0.80 \\
\hline ICS/LABA & 321 (12.6\%) & $38(18.7 \%)$ & $283(12.2 \%)$ & 0.01 \\
\hline ICS/LABA/LAMA & $613(24.0 \%)$ & 39 (19.2\%) & $569(24.6 \%)$ & 0.10 \\
\hline \multicolumn{5}{|l|}{ Comorbidities } \\
\hline Diabetes mellitus & $423(16.9 \%)$ & $24(12.2 \%)$ & 399 (17.5\%) & 0.07 \\
\hline Hypertension & 987 (39.5\%) & 81 (40.9\%) & 897 (39.3\%) & 0.72 \\
\hline Osteoporosis & $103(4.1 \%)$ & $36(18.3 \%)$ & $64(2.8 \%)$ & $<0.01$ \\
\hline Gastroesophageal reflux disease & $232(93 \%)$ & $22(11.2 \%)$ & $207(9.1 \%)$ & 0.40 \\
\hline \multicolumn{5}{|l|}{ History of respiratory and allergic diseases } \\
\hline Bronchiectasis & 185 (7.5\%) & $23(12.0 \%)$ & $162(7.2 \%)$ & 0.02 \\
\hline TB & $623(25.0 \%)$ & $58(29.9 \%)$ & $559(24.5 \%)$ & 0.12 \\
\hline Respiratory infection in childhood & $483(19.7 \%)$ & $64(32.7 \%)$ & $413(18.5 \%)$ & $<0.01$ \\
\hline Asthma & $799(32.1 \%)$ & $86(44.1 \%)$ & 709 (31.2\%) & $<0.01$ \\
\hline BDI score $\#$ & $8.6 \pm 12.1$ & $13.0 \pm 19.3$ & $8.3 \pm 11.3$ & 0.03 \\
\hline Moderate to severe depression $(\mathrm{BD}|>| 8)$ & $150(12.6 \%)$ & $18(22.2 \%)$ & $132(1 \mid .8 \%)$ & 0.01 \\
\hline
\end{tabular}

Notes: Data are presented as $\mathrm{n}(\%)$ or mean \pm SD, unless otherwise stated. ${ }^{B}$ BDI: Beck Depression Inventory; 0-9 indicates minimal depression, $10-18$ indicates mild depression, 19-29 indicates moderate depression, 30-63 indicates severe depression.

Abbreviations: BMI, body mass index; LAMA, long-acting muscarinic antagonist; LABA, long-acting beta2-agonist; ICS, inhaled corticosteroids. 
respectively). Female patients also had higher BDI scores $(13.0 \pm 1.93$ vs $8.3 \pm 11.3$, respectively) and a higher rate of moderate to severe depression $(22.2 \%$ vs $11.8 \%$, respectively).

\section{COPD Symptoms, Functional Exercise}

\section{Capacity, and Acute Exacerbations}

Table 2 presents the differences in COPD symptoms and functional exercise capacity of female vs male COPD patients. Chronic bronchitis, assessed using questionnaires, as well as the mMRC, SGRQ-C, and CAT scores, indicated more severe symptoms in female than in male patients, but only the differences in mMRC and CAT scores were significant. An analysis of the subquestionnaires of the CAT score revealed that females had greater limitations in home activities and poorer sleep as a result of their lung conditions (Table S-1). Table S-2 lists the results of the sub-questionnaires of the SGRQ-C score. Males had better functional exercise capacity than females, as assessed using the 6-minute walk distance test ( $366.3 \pm 89.9$ vs $384.6 \pm 120.5$, respectively).

A comparison between males and females of the number of COPD exacerbations in one year (Table 3) revealed no significant differences in the number of moderate to severe or severe exacerbations per year. Males and females also did not differ in terms of need for mechanical ventilation during hospitalization.

\section{Radiologic Findings}

Chest X-ray and computed tomography (CT) images of the male and female COPD patients were compared (Table 4). Female patients had a larger number of abnormal imaging features than males, but only the difference in the chest $\mathrm{X}$-ray findings was significant. However, chest $\mathrm{CT}$ was better

Table 2 Differences of Symptoms and Functional Exercise Capacity Between Female and Male COPD Patients

\begin{tabular}{|l|l|l|l|}
\hline & $\begin{array}{l}\text { Female } \\
(\mathbf{N}=203)\end{array}$ & $\begin{array}{l}\text { Male } \\
(\mathbf{N}=23 \text { I2) }\end{array}$ & P-value \\
\hline $\begin{array}{l}\text { Chronic bronchitis } \\
\text { symptoms }\end{array}$ & $26(13.1 \%)$ & $237(10.4 \%)$ & 0.30 \\
mMRC score & $1.6 \pm 0.9$ & $1.3 \pm 0.9$ & $<0.01$ \\
SGRQ score & $35.9 \pm 19.3$ & $33.5 \pm 19.1$ & 0.16 \\
CAT score & $16.0 \pm 8.2$ & $14.7 \pm 8.0$ & 0.02 \\
6MWT, meters & $366.3 \pm 89.9$ & $384.6 \pm 120.5$ & 0.02 \\
\hline
\end{tabular}

Notes: Data are presented as $\mathrm{n}(\%)$ or mean \pm SD, unless otherwise stated. Abbreviations: mMRC, modified Medical Research Council; SGRQ-C, St. George's Respiratory Questionnaire for COPD; CAT, COPD Assessment Test; 6MWT, 6-minute walk distance test.
Table 3 Gender Difference of COPD Exacerbation (per Year)

\begin{tabular}{|l|l|l|l|l|}
\hline & $\begin{array}{l}\text { Female } \\
\mathbf{( N = 2 0 3 )}\end{array}$ & $\begin{array}{l}\text { Male } \\
\mathbf{( N = 2 3 ~ 1 2 )}\end{array}$ & $\begin{array}{l}\text { Total } \\
\mathbf{( N = 2 5 ~ I 5 )}\end{array}$ & p-value \\
\hline $\begin{array}{l}\text { Moderate to } \\
\text { severe exacerbation } \\
\text { Severe exacerbation }\end{array}$ & $0.6 \pm 1.5$ & $0.5 \pm 1.3$ & $0.5 \pm 1.4$ & 0.44 \\
$\begin{array}{l}\text { Applying MV during } \\
\text { hospitalization }\end{array}$ & $1(1.0 \%)$ & $14(1.2 \%)$ & $15(1.2 \%)$ & 1.00 \\
\hline
\end{tabular}

Abbreviation: MV, mechanical ventilation.

than chest X-ray at detecting abnormal findings in both sexes. In the assessment of specific findings, emphysema was more common in males and bronchiectasis in females, both on chest X-ray and CT. With regard to the features of tuberculosis-destroyed lung and airway wall thickening, the differences between the two sexes were not significant.

\section{Pulmonary Function Tests}

An analysis of PFT results at enrollment (Table 5) revealed that post-bronchodilator $\mathrm{FEV}_{1} \%$ predicted and $\mathrm{FEV}_{1} / \mathrm{FVC}$ were significantly higher in female than in male patients $(66.2 \pm 21.5$ vs $61.6 \pm 19.2 ; 55.9 \pm 11.2$ vs $50.8 \pm 12.5$, respectively) whereas the absolute volumes of $\mathrm{FEV}_{1}$ and FVC were lower in females than in males $(1.3 \pm 0.5$ vs 1.7 $\pm 1.3 ; 2.3 \pm 0.6$ vs $3.3 \pm 0.8$, respectively). On the PFTs, $\mathrm{DL}_{\mathrm{CO}}$ was significantly higher in male patients $(69.0 \pm 20.0$ vs 73.7 \pm 23.2 , respectively), and RV/TLC was significantly higher in female patients $(47.0 \pm 13.8$ vs $43.8 \pm 14.1$, respectively).

Table 4 Comparisons of Radiologic Features Between Female and Male COPD Patients

\begin{tabular}{|c|c|c|c|}
\hline & $\begin{array}{l}\text { Female } \\
(N=203)\end{array}$ & $\begin{array}{l}\text { Male } \\
(\mathrm{N}=2303)\end{array}$ & p-value \\
\hline \multicolumn{4}{|l|}{ Chest $\mathrm{X}$-ray result } \\
\hline Abnormal & I 32 (75.9\%) & I335 (67.4\%) & 0.03 \\
\hline Normal & $42(24.1 \%)$ & 647 (32.6\%) & \\
\hline Emphysematous change & $19(\mid 4.0 \%)$ & $536(30.0 \%)$ & $<0.01$ \\
\hline TB destroyed lung & II (8.I\%) & $109(6.1 \%)$ & 0.46 \\
\hline Airway wall thickening & $8(5.9 \%)$ & $48(2.7 \%)$ & 0.06 \\
\hline Bronchiectasis & $20(14.7 \%)$ & $93(5.2 \%)$ & $<0.01$ \\
\hline \multicolumn{4}{|l|}{ Chest CT Result } \\
\hline Abnormal & 110 (95.7\%) & 1129 (9I.9\%) & 0.21 \\
\hline Normal & $5(4.3 \%)$ & $99(8.1 \%)$ & \\
\hline Emphysematous change & $17(23.0 \%)$ & $515(56.3 \%)$ & $<0.01$ \\
\hline TB destroyed lung & $6(8.1 \%)$ & $62(6.8 \%)$ & 0.84 \\
\hline Airway wall thickening & $10(13.5 \%)$ & $110(12.0 \%)$ & 0.85 \\
\hline Bronchiectasis & $17(23.0 \%)$ & $119(13.0 \%)$ & 0.03 \\
\hline
\end{tabular}


Table 5 Differences of Lung Function Between Female and Male COPD Patients

\begin{tabular}{|c|c|c|c|}
\hline Subjects $n$. & $\begin{array}{l}\text { Female } \\
(N=146)\end{array}$ & $\begin{array}{l}\text { Male } \\
(N=|5| 6)\end{array}$ & P-value \\
\hline $\mathrm{FEV}_{\text {I }}$ (absolute, L) & $1.3 \pm 0.5$ & $1.7 \pm 1.3$ & $<0.01$ \\
\hline FEV (\% predicted) & $66.2 \pm 21.5$ & $61.6 \pm 19.2$ & $<0.01$ \\
\hline FVC (absolute, L) & $2.3 \pm 0.6$ & $3.3 \pm 0.8$ & $<0.01$ \\
\hline FVC (\% predicted) & $85.6 \pm 17.9$ & $84.8 \pm 18.2$ & 0.55 \\
\hline $\mathrm{FEV}_{\mathrm{I}} / \mathrm{FVC}(\%)$ & $55.9 \pm 11.2$ & $50.8 \pm 12.5$ & $<0.01$ \\
\hline $\mathrm{DL}_{\mathrm{co}}, \%$ predicted & $69.0 \pm 20.0$ & $73.7 \pm 23.2$ & $<0.01$ \\
\hline RV/TLC (\%) & $47.0 \pm 13.8$ & $43.8 \pm 14.1$ & 0.02 \\
\hline
\end{tabular}

As shown in Figure 1, $\mathrm{FEV}_{1}$ declined by $47 \mathrm{~mL}$ per year in male patients but improved by $23 \mathrm{~mL}$ per year in female patients $(p<0.01)$. In females, $\mathrm{FEV}_{1}$ increased by $32 \mathrm{~mL}$ between the first and second year of follow-up. The total volume of $\mathrm{FEV}_{1}$ loss in 5 years was $196 \mathrm{~mL}$ in female and $213 \mathrm{~mL}$ in male patients.

\section{Discussions}

In this study, multicenter COPD cohort data were analyzed to explore sex-specific differences in the clinical parameters of COPD patients, including general characteristics, symptoms, acute exacerbations, radiologic findings, and PFT results. Female patients differed from male patients in that fewer were smokers but their exposure to passive smoking or biomass was greater; they also had higher rates of bronchiectasis and more respiratory infections during childhood. Additionally, compared to male COPD patients, females with COPD experienced more symptoms and had a worse functional exercise capacity, as assessed by symptom scores and questionnaires. However, no differences were observed in terms of COPD exacerbations between the two groups. Based on the radiologic findings, bronchiectatic COPD was more common in females and emphysematous COPD was more common in males. The PFT results in female patients revealed less obstructive disease but a higher RV/TLC. The latter is a clinical marker for air trapping and resting

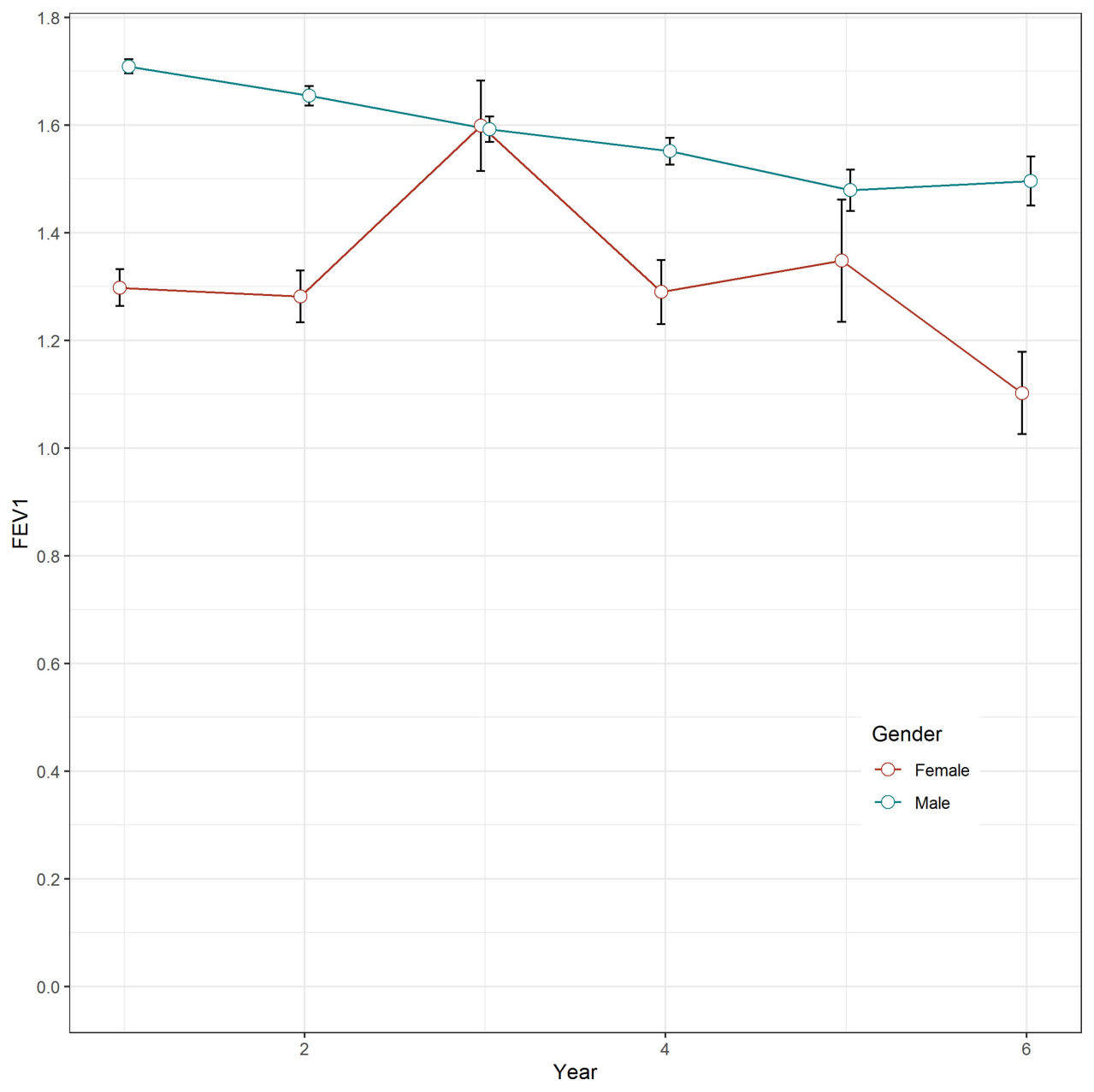

Figure I Gender difference of FEVI decline. 
pulmonary hyperinflation. According to the longitudinal analysis of the 5-year $\mathrm{FEV}_{1}$ data, lung function declined more rapidly in male than in female patients.

The sexual distribution of COPD has been the subject of several studies. A meta-analysis of 194 studies reported a prevalence of COPD of $9.23 \%$ in males and $6.16 \%$ in females. $^{2}$ However, the meta-analysis also revealed that sexual differences in the prevalence of COPD varied according to factors such as the timeline of the study, the definition of COPD, and the socioeconomic status of the patients. Based on the National Health and Nutrition Examination Survey (NHANES) reports I-III, between 1971 and 1994 the prevalence of COPD in the USA increased from 50.8 per 1000 to 58.2 per 1000 in females, while decreasing from 108.1 per 1000 to 74.3 per 1000 in males. $^{3}$ This trend can perhaps be attributed to an increase in cigarette smoking by women, their greater hormonal susceptibility to the adverse effects of cigarette smoke, and also to genetic predispositions. ${ }^{9}$ Similar results of a relatively high prevalence of COPD in females have been reported in studies from Canada, Austria, and the Netherlands. $^{2,4-6}$ In the USA, the self-reported prevalence of COPD between 1998 and 2009 was higher in females than in males. ${ }^{7}$ However, as COPD may be underdiagnosed and thus under-self-reported in females, the difference may be even larger and the sex-related shift in COPD in developed countries may be even more pronounced. In contrast, in developing regions including Latin America, India, and China, COPD is considered a disease of men. ${ }^{17-19}$ This difference between developed and developing countries may be related to the larger number of women smokers in developed countries, where there are fewer differences between the lifestyles of men and women. ${ }^{3,8}$ In our study, $90.5 \%$ of the COPD patients were male, consistent with the lower percentage of female than male smokers in Korea (7.5\% vs $36.7 \%$, respectively). ${ }^{20}$ However, smoking history alone may not fully explain the $>9$ times higher prevalence of COPD in Korean men than women. Thus, further studies are needed to elucidate the reason for this very large difference.

In contrast to tobacco smoking, our study revealed that biomass exposure and passive smoking were more frequent in female COPD patients. A previous study reported that biomass is a strong risk factor for COPD in females in developing countries. ${ }^{10}$ Our data also revealed that biomass exposure in female and male COPD patients is higher in South Korea than in other developing countries, such as China. ${ }^{21}$ This observation can be explained by the rapid change in Korea from a developing to a developed country, such that lifetime biomass exposure has increased as well. Moreover, until few decades ago, wood was the main fuel for cooking and heating, with women traditionally being responsible for both, such that their exposure to biomass would have been accordingly higher.

In our study, male patients were more likely to have emphysema, whereas females were more likely to have bronchiectasis, as determined from the clinical histories and radiologic findings. A higher proportion of emphysema in male COPD patients was previously reported in studies based on CT imaging, ${ }^{12,22}$ one of which reported a significantly higher emphysema index and lower mean wall area percentage in nonsmoking male patients. ${ }^{22}$ This result suggests that men are more predisposed to the emphysema phenotype of COPD, regardless of their smoking history. However, our finding of a higher proportion of bronchiectasis in females with COPD is inconsistent with the results of a meta-analysis of 6 observational studies involving 881 patients. ${ }^{13}$ The discrepancy may be due to the higher rate of respiratory infections during childhood among the women enrolled in our study.

Symptoms associated with COPD, such as cough, sputum, and dyspnea, are more frequent in women than in men. ${ }^{3,23-25}$ While previous studies have mostly evaluated subjective symptoms using mMRC or SGRQ scores, our data also included CAT scores, which differed significantly between males and females, with a 1.3-point higher score in the latter. The results of the 6-minute walk distance test were worse in females, indicating their reduced functional exercise capacity. A previous study reported a nonsignificant difference in this test, probably due to the small size of its study population. ${ }^{23}$ Poor scores related to symptoms and functional exercise capacity may be associated with a higher prevalence of depression and anxiety, as suggested by our results as well as those of previous studies. ${ }^{26,27}$ Also, although we did not observe significant differences in previous exacerbations between female and male COPD patients, previous studies have reported higher exacerbation rates in females. ${ }^{11,14}$ This was not the case for the PFT results in our study population, in which males had worse $\mathrm{FEV}_{1}$ and $\mathrm{FEV}_{1} / \mathrm{FVC}$ values than females, a finding consistent with nationwide multicenter studies from Spain and China. ${ }^{14,15}$ The discordance between symptom and exacerbation rate on one hand, and the PFT results on the other, may be due to a higher rate of asthma-COPD overlap in females, as observed in this and other studies. ${ }^{28,29}$ 
Several population-based studies have reported steeper annual $\mathrm{FEV}_{1}$ declines in men than in women. ${ }^{30-33}$ However, our linear mixed model revealed an improvement in annual $\mathrm{FEV}_{1}$ in women, but a significant decrease in the mean $\mathrm{FEV}_{1}$ over 5 years $(196 \mathrm{~mL}$ in females, $213 \mathrm{~mL}$ in males). There may be several reasons for this difference. First, our data revealed an unexplained improvement in $\mathrm{FEV}_{1}$ in female patients during the second year of follow up, which may have affected the result. Second, cigarette smoking causes a steeper $\mathrm{FEV}_{1}$ decline in men than in women, whereas the cessation of smoking leads to a greater $\mathrm{FEV}_{1}$ improvement in women, such that differences in the smoking histories of our patients may have influenced the results. ${ }^{34,35}$ Furthermore, a previous study reported that female patients with mild obstruction and a higher $\mathrm{FEV}_{1} / \mathrm{FVC}$ have a significantly smaller decline in $\mathrm{FEV}_{1}{ }^{36}$ Because the women in our study had a notably higher $\mathrm{FEV}_{1} / \mathrm{FVC}$ compared with those in previous studies, they may have also had a smaller annual decline in $\mathrm{FEV}_{1}$. Finally, drug compliance, cessation of smoking during the study period, and the proportion of overlapping asthma may have been important factors explaining the difference in the $\mathrm{FEV}_{1}$ decline. Definitive answers will require further studies.

Our study had several limitations. First, the hospitals treating our cohort of patients were mainly tertiary hospitals, such that our study population may not have accurately represented the general COPD population. Second, we have no explanation for the remarkable improvement in $\mathrm{FEV}_{1}$ that occurred in our female patients during the second year of follow-up but this may have affected the analysis of the annual $\mathrm{FEV}_{1}$ change. Third, only $8.1 \%$ of the COPD population recruited for this study was female. The use of propensity score matching in further analyses will avoid this large difference. Finally, our study had a cross-sectional design, so more longitudinal research will be needed to explore important parameters including symptom scores and exacerbation.

In conclusion, we analyzed the sex-based differences in the clinical parameters of COPD patients. The results revealed that fewer female patients were smokers but exposure to passive smoking and biomass was higher in females than in males. Female patients had more COPD symptoms and a poorer functional exercise capacity, which may be explained by the result that female COPD patients were more likely to be asthmatic and were more depressed than males with COPD. The exacerbation rates did not significantly differ from those of male patients but revealed less annual $\mathrm{FEV}_{1}$ loss in females than in males. Gender difference of Korean female COPD showed similar to that of developing countries. Clinicians should be aware of typical characteristics of female COPD such as depression, and keep in mind that female without smoking history may also develop COPD.

\section{Funding}

This research was supported by Research of Korea Centers for Disease Control and Prevention (2016ER670100, 2016ER670101, 2016ER670102 and 2018ER670100, 2018ER670101, 2018ER670102)

\section{Disclosure}

The authors have no conflicts of interest.

\section{References}

1. Lopez-Campos JL, Tan W, Soriano JB. Global burden of COPD. Respirology. 2016;21(1):14-23. doi:10.1111/resp.12660

2. Ntritsos G, Franek J, Belbasis L, et al. Gender-specific estimates of COPD prevalence: a systematic review and meta-analysis. Int J Chron Obstruct Pulmon Dis. 2018;13:1507-1514. doi:10.2147/COPD.S146390

3. Aryal S, Diaz-Guzman E, Mannino DM. COPD and gender differences: an update. Transl Res. 2013;162(4):208-218. doi:10.1016/j. trs1.2013.04.003

4. Gershon AS, Wang C, Wilton AS, Raut R, To T. Trends in chronic obstructive pulmonary disease prevalence, incidence, and mortality in ontario, Canada, 1996 to 2007: a population-based study. Arch Intern Med. 2010;170(6):560-565. doi:10.1001/archinternmed.2010.17

5. Bischoff EW, Schermer TR, Bor H, Brown P, van Weel C, van den Bosch WJ. Trends in COPD prevalence and exacerbation rates in Dutch primary care. Br J Gen Pract. 2009;59(569):927-933. doi:10.3399/bjgp09X473079

6. Schirnhofer L, Lamprecht B, Vollmer WM, et al. COPD prevalence in salzburg, austria: results from the burden of obstructive lung disease (BOLD) study. Chest. 2007;131(1):29-36. doi:10.1378/chest.06-0365

7. Akinbami LJ, Liu X. Chronic obstructive pulmonary disease among adults aged 18 and over in the United States, 19982009. NCHS Data Brief. 2011;(63):1-8.

8. WHO. WHO report on the global tobacco epidemic. 2019. Available from: https://www.who.int/tobacco/global_report/en/. Accessed September 05, 2020.

9. Sansores RH, Ramirez-Venegas A. COPD in women: susceptibility or vulnerability? Eur Respir J. 2016;47(1):19-22. doi:10.1183/ 13993003.01781-2015

10. Varkey AB. Chronic obstructive pulmonary disease in women: exploring gender differences. Curr Opin Pulm Med. 2004;10 (2):98-103. doi:10.1097/00063198-200403000-00003

11. Agusti A, Calverley PM, Celli B, et al. Characterisation of COPD heterogeneity in the ECLIPSE cohort. Respir Res. 2010;11:122. doi:10.1186/1465-9921-11-122

12. Dransfield MT, Washko GR, Foreman MG, Estepar RS, Reilly J, Bailey WC. Gender differences in the severity of CT emphysema in COPD. Chest. 2007;132(2):464-470. doi:10.1378/chest.07-0863

13. Ni Y, Shi G, Yu Y, Hao J, Chen T, Song H. Clinical characteristics of patients with chronic obstructive pulmonary disease with comorbid bronchiectasis: a systemic review and meta-analysis. Int $J$ Chron Obstruct Pulmon Dis. 2015;10:1465-1475. doi:10.2147/COPD. S83910 
14. Naberan K, Azpeitia A, Cantoni J, Miravitlles M. Impairment of quality of life in women with chronic obstructive pulmonary disease. Respir Med. 2012;106(3):367-373. doi:10.1016/j.rmed.20 11.09 .014

15. Jia G, Lu M, Wu R, Chen Y, Yao W. Gender difference on the knowledge, attitude, and practice of COPD diagnosis and treatment: a national, multicenter, cross-sectional survey in China. Int J Chron Obstruct Pulmon Dis. 2018;13:3269-3280. doi:10.2147/COPD. S176173

16. Myong JP, Yoon HK, Rhee CK, Kim HR, Koo JW. Risk factors for lung function impairment among the general non-smoking Korean population. Int J Tuberc Lung Dis. 2015;19(9):1019-1026, i-iii. doi:10.5588/ijtld.14.0929

17. Menezes AM, Perez-Padilla R, Jardim JR, et al. Chronic obstructive pulmonary disease in five Latin American cities (the PLATINO study): a prevalence study. Lancet. 2005;366(9500):1875-1881. doi:10.1016/S0140-6736(05)67632-5

18. Bhome AB. COPD in India: iceberg or volcano? J Thorac Dis. 2012;4(3):298-309. doi:10.3978/j.issn.2072-1439.2012.03.15

19. Zhong N, Wang C, Yao W, et al. Prevalence of chronic obstructive pulmonary disease in China: a large, population-based survey. Am $J$ Respir Crit Care Med. 2007;176(8):753-760. doi:10.1164/ rccm.200612-17490C

20. Korea Centers for Disease Control. Korea national health \& nutrition examination survey. Available from: https://knhanes.cdc.go.kr/ knhanes/eng/index.do. Accessed September 05, 2020.

21. Lou P, Zhu Y, Chen P, et al. Vulnerability of patients with chronic obstructive pulmonary disease according to gender in China. Int J Chron Obstruct Pulmon Dis. 2012;7:825-832. doi:10.2147/ COPD.S37447

22. Hong Y, Ji W, An S, Han SS, Lee SJ, Kim WJ. Sex differences of COPD phenotypes in nonsmoking patients. Int $J$ Chron Obstruct Pulmon Dis. 2016;11:1657-1662. doi:10.2147/COPD.S108343

23. Kapustina V, Ovcharenko S. Gender differences in COPD patients. European Respiratory J. 2014;44(Suppl 58):P3574. doi:10.1183/ 09031936.00003814

24. Watson L, Vestbo J, Postma DS, et al. Gender differences in the management and experience of chronic obstructive pulmonary disease. Respir Med. 2004;98(12):1207-1213. doi:10.1016/j.rmed. 2004.05.004
25. Gut-Gobert C, Cavailles A, Dixmier A, et al. Women and COPD: do we need more evidence? Eur Respir Rev. 2019;28:151. doi:10.1183/ $16000617.0055-2018$

26. Di Marco F, Verga M, Reggente M, et al. Anxiety and depression in COPD patients: the roles of gender and disease severity. Respir Med. 2006;100(10):1767-1774. doi:10.1016/j.rmed.2006.01.026

27. Kunik ME, Roundy K, Veazey C, et al. Surprisingly high prevalence of anxiety and depression in chronic breathing disorders. Chest. 2005;127(4):1205-1211. doi:10.1378/chest.127.4.1205

28. Wheaton AG, Pleasants RA, Croft JB, et al. Gender and asthma-chronic obstructive pulmonary disease overlap syndrome. J Asthma. 2016;53(7):720-731. doi:10.3109/02770903.2016.1154072

29. Nielsen M, Bårnes CB, Ulrik CS. Clinical characteristics of the asthma-COPD overlap syndrome-a systematic review. Int J Chron Obstruct Pulmon Dis. 2015;10:1443-1454. doi:10.2147/COPD. S85363

30. Perez-Padilla R, Fernandez-Plata R, Montes de Oca M, et al. Lung function decline in subjects with and without COPD in a population-based cohort in Latin-America. PLoS One. 2017;12(5): e0177032. doi:10.1371/journal.pone.0177032

31. Leem AY, Park B, Kim YS, Chang J, Won S, Jung JY. Longitudinal decline in lung function: a community-based cohort study in Korea. Sci Rep. 2019;9(1):13614. doi:10.1038/s41598-019-49598-9

32. Omori H, Nonami Y, Morimoto Y. Effect of smoking on FEV decline in a cross-sectional and longitudinal study of a large cohort of Japanese males. Respirology. 2005;10(4):464-469. doi:10.1111/ j.1440-1843.2005.00727.x

33. Chinn S, Jarvis D, Melotti R, et al. Smoking cessation, lung function, and weight gain: a follow-up study. Lancet. 2005;365(9471):1629-1635; discussion 1600-1621. doi:10.1016/S0140-6736(05)66511-7

34. Connett JE, Murray RP, Buist AS, et al. Changes in smoking status affect women more than men: results of the lung health study. $\mathrm{Am}$ $J$ Epidemiol. 2003;157(11):973-979. doi:10.1093/aje/kwg083

35. Anthonisen NR, Connett JE, Murray RP. Smoking and lung function of lung health study participants after 11 years. Am J Respir Crit Care Med. 2002;166(5):675-679. doi:10.1164/rccm.2112096

36. Watson L, Vonk JM, Lofdahl CG, et al. Predictors of lung function and its decline in mild to moderate COPD in association with gender: results from the Euroscop study. Respir Med. 2006;100(4):746-753. doi:10.1016/j.rmed.2005.08.004

\section{Publish your work in this journal}

The International Journal of COPD is an international, peer-reviewed journal of therapeutics and pharmacology focusing on concise rapid reporting of clinical studies and reviews in COPD. Special focus is given to the pathophysiological processes underlying the disease, intervention programs, patient focused education, and self management protocols. This journal is indexed on PubMed Central, MedLine and CAS. The manuscript management system is completely online and includes a very quick and fair peer-review system, which is all easy to use. Visit http://www.dovepress.com/testimonials.php to read real quotes from published authors. 